\title{
Downregulation of TES by hypermethylation in glioblastoma reduces cell apoptosis and predicts poor clinical outcome
}

\author{
Yu Bai ${ }^{1}$, Quan-Geng Zhang ${ }^{2 *}$ and Xin-Hua Wang ${ }^{1 *}$
}

\begin{abstract}
Background: Gliomas are the most common human brain tumors. Glioblastoma, also known as glioblastoma multiform (GBM), is the most aggressive, malignant, and lethal glioma. The investigation of prognostic and diagnostic molecular biomarkers in glioma patients to provide direction on clinical practice is urgent. Recent studies demonstrated that abnormal DNA methylation states play a key role in the pathogenesis of this kind of tumor. In this study, we want to identify a novel biomarker related to glioma initiation and find the role of the glioma-related gene.

Methods: We performed a methylation-specific microarray on the promoter region to identify methylation gene(s) that may affect outcome of GBM patients. Normal and GBM tissues were collected from Tiantan Hospital. Genomic DNA was extracted from these tissues and analyzed with a DNA promoter methylation microarray. Testis derived transcript (TES) protein expression was analyzed by immunohistochemistry in paraffin-embedded patient tissues. Western blotting was used to detect TES protein expression in the GBM cell line U251 with or without 5-aza-dC treatment. Cell apoptosis was evaluated by flow cytometry analysis using Annexin V/PI staining.
\end{abstract}

Results: We found that the TES promoter was hypermethylated in GBM compared to normal brain tissues under DNA promoter methylation microarray analysis. The GBM patients with TES hypermethylation had a short overall survival ( $P<0.05$, log-rank test). Among GBM samples, reduced TES protein level was detected in 33 (89.2\%) of 37 tumor tissues by immunohistochemical staining. Down regulation of TES was also correlated with worse patient outcome ( $P<0.05$, log-rank test). Treatment on the GBM cell line U251 with 5-aza-dC can greatly increase TES expression, confirming the hypermethylation of TES promoter in GBM. Up-regulation of TES prompts U251 apoptosis significantly. This study demonstrated that both TES promoter hypermethylation and down-regulated protein expression significantly correlated with worse patient outcome. Treatment on the GBM cell line (U251) with 5-aza-dC can highly release TES expression resulting in significant apoptosis in these cells.

Conclusions: Our findings suggest that the TES gene is a novel tumor suppressor gene and might represent a valuable prognostic marker for glioblastoma, indicating a potential target for future GBM therapy.

Keywords: Clinical outcome, DNA promoter methylation microarray, Glioblastoma, Testis derived transcript

\footnotetext{
* Correspondence: zhangqg@ccmu.edu.cn; jinsemujin@163.com

2Department of Immunology, Capital Medical University, Beijing 100069,

China

'Department of Blood transfusion, The Central Hospital of China Aerospace

Corporation, Beijing 100049, China
}

\section{Ciomed Central}

2014 Bai et al.; licensee BioMed Central. This is an Open Access article distributed under the terms of the Creative Commons Attribution License (http://creativecommons.org/licenses/by/4.0), which permits unrestricted use, distribution, and reproduction in any medium, provided the original work is properly credited. The Creative Commons Public Domain Dedication waiver (http://creativecommons.org/publicdomain/zero/1.0/) applies to the data made available in this article unless otherwise stated. 


\section{Background}

Gliomas are the most common central nervous system tumor in adults. Glioblastoma, also known as glioblastoma multiform (GBM), is the most aggressive, malignant, and lethal glioma. Despite radiation and temozolomide therapy, the prognosis of patients with GBM remains extremely poor, with a median survival time of only 14.5 months from diagnosis to death [1-3]. Recently, DNA methylation alterations have been widely reported in human gliomas, including global hypomethylation and promoter-associated $\mathrm{CpG}$ island hypermethylation [4]. To better understand the molecular mechanisms and pathological effects of genomic methylation abnormality on GBM, we performed genome-wide DNA methylation analysis on GBM $(\mathrm{n}=42)$ and normal brain tissues $(\mathrm{n}=8)$. We found that the testis derived transcript (TES) gene promoter was broadly hypermethylated in GBM patients.

The TES gene encodes a protein (Tes) of 421 amino acids which plays a role in protein protein interactions $[5,6]$. TES has an important role in cell adhesions and largely affects cell motility in a vast number of cancers [7]. According to recent studies, TES is widely considered as a putative tumor suppressor gene in malignances such as head and neck squamous cell carcinomas [8], ovarian cancer [9], primary gastric cancer [10], and prostate cancer [11]. However, TES methylation status and pathological function in GBM still remain largely unclear $[12,13]$.

Herein, we examined the expression of TES in human GBMs and investigated the biological role of TES in the pathogenesis of this tumor. We found that TES was down-regulated in both glioblastoma cell lines and GBM tissues. TES expression level correlated inversely with the clinical outcome. Our results also indicate that downregulation of TES protein expression is anti-apoptotic to GBM cell line.

\section{Methods}

\section{Tissue samples}

All samples were collected from the Department of Neurosurgery, Beijing Tiantan Hospital, between June 2009 and June 2012. Tissues were frozen in liquid nitrogen immediately after surgery; some were stored at $-80 \mathrm{C}$ following the extraction of RNA, whereas others were formalin-fixed and paraffin-embedded for immunohistochemistry. Informed consent from patients and ethics approval from the ethics committee was achieved. This study have been approved by the Review board of Beijing Tiantan Hospital, Capital Medical University.

\section{DNA methylation profiling}

Methylation profiling was performed using the Illumina Infinium Methylation27 Bead Array. The BeadChip contains
27,578 highly informative CpG sites covering more than 14,000 human RefSeq genes. This allows searches to interrogate all these sites per sample at a single nucleotide resolution. Bisulfite modification of DNA, chip processing, and data analysis were carried out by following the manufacturers manual. DNA was extracted from peripheral-blood buffy coats using the QIAmp DNA mini kit according to the manufacturer s protocol (Qiagen, Valencia, CA, USA); the quality of DNA samples was assessed by electrophoresis in a $1 \%$ agarose gel. DNA were then bisulfite-modified using the EZ DNA methylation kit (Zymo Research) and hybridized according to the manufacturers instructions.

\section{Immunohistochemistry}

For immunohistochemistry, we used a standard avidinbiotin-peroxidase complex method. Briefly, 4- $\mu \mathrm{m}$ thick tissue sections were dewaxed and the endogenous peroxidase activity was blocked with $3 \%$ hydrogen peroxide in deionized water. For antigen retrieval, sections were immersed in an antigen repair liquid kit and then rinsed in phosphate-buffered saline (PBS; $\mathrm{pH} 7.2$ ). The sections were incubated at $37 \mathrm{C}$ for $1 \mathrm{~h}$ with anti-TES monoclonal antibody. After rinsing in PBS, sections were incubated with a goat anti-mouse secondary antibody for 30 min, and washed in PBS. A DAB coloration kit (ZSGBBIO ORIGENE, ZLI-9018) was then used; PBS was used as a negative control. The percentage of positive tumor cells was counted under a bright-field Olympus microscope. Sections with fewer than $25 \%$ labeled cells indicated low expression of TES. Sections with labeling of $\geq 25 \%$ indicated high expression of TES.

\section{Cell lines and treatment with 5-Aza-2'-deoxycytidine (5-aza-dC) treatment}

Glioblastoma cell lines (U251) were routinely cultured in Dulbeccos modified eagle medium (Hyclone, Thermo Scientific, USA). The medium was supplemented with $1 \%$ L-glutamine (Hyclone), 10\% fetal bovine serum (Gibco, Invitrogen Corporation, Carlsbad, CA, USA), 1\% penicillin streptomycin (Hyclone), and grown at $37 \mathrm{C}$ in a humidified atmosphere of $5 \% \mathrm{CO}_{2} / 95 \%$ air. 5-aza-dC (Sigma Aldrich Corporation, St Louis, MO, USA) was dissolved in PBS (Hyclone) and filtered with a $0.22 \mu \mathrm{m}$ filter membrane.

\section{Western blotting}

U251 cells were lysed in 1\% NP40 buffer (150 mM, 1\% NP40, $50 \mathrm{Mm}$ Tris, $\mathrm{pH}$ 8.0) following treatment with 5 -aza-dC; $30 \mu \mathrm{g}$ of protein samples were loaded onto $10 \%$ SDS-PAGE gels and then transferred to polyvinylidene fluoride membranes (Millipore). The membranes were then blocked with skimmed milk in Tris-buffered saline Tween-20 for $2 \mathrm{~h}$. The following primary antibodies 
were used: anti-TES (Abcam, Cambridge, MA, USA) and anti-b-tubulin (Sigma-Aldrich), followed by reaction with a goat anti-mouse second antibody.

\section{Flow cytometry analysis of cell apoptosis}

Cell apoptosis was analyzed by an Annexin V-FITCpropidium iodide (PI) kit according to the manufacturer $\mathrm{s}$ instructions. Briefly, harvested cells were resuspended in $100 \mu \mathrm{L}$ Annexin V-FITC binding buffer and adjusted to about $110^{6} / \mathrm{mL}$, then $5 \mu \mathrm{L}$ Annexin V-FITC and $5 \mu \mathrm{L}$ PI $(20 \mathrm{mg} / \mathrm{mL})$ were added and incubated for $15 \mathrm{~min}$ at room temperature in the dark. Flow cytometry was conducted on a fluorescence-activated cell sorter (FACSCalibur BD Biosciences, Hercules, CA, USA). Each experiment was performed in triplicate.

\section{Statistical analysis}

Cox analysis was performed using Matlab2009. Survival curves were calculated according to the Kaplan-Meier method and differences between curves were assessed using the log-rank test. The difference between high and low TES-expressing tissues was assessed using the $\chi^{2}$ test. Significant differences among groups were determined using the Students $t$-test. $P<0.05$ was considered to be significant. All statistical analyses were carried out using the software GraphPad Prism (GraphPad Software, La Jolla, CA, USA) and SPSS version 16.0 (SPSS, Chicago, IL, USA).

\section{Results and discussion}

Identification of promoter hypermethylation of TES gene in GBM

We performed genome-wide DNA methylation analysis on $42 \mathrm{GBM}$ and 8 normal brain tissues. To identify genes that had different methylation status between pGBM and normal tissues, all 50 methylation data were subjected to Significant Analysis of Microarray and 42 GBM were analyzed by Survival Analysis (Cox analysis) Metlab2009. Overall, 21 differential genes displayed correlation between promoter methylation and the overall survival in glioblastomas: TUBA2, CKMT2, AMT, HOXC11, TRIM58, LCE1B, KLF14, SERPINB12, CYP2A7, TREML2, UNQ467, SPRR3, TES, RGN, DEFA1, AJAP1, PDE4C, SPRR2D, $W N T 7 B, U B Q L N 3$, and $L C E 1 F$. Independent $t$-test and Kaplan-Meier method were performed on these genes to identify the differentiation and prognostic value in a univariate manner. Finally, eight genes were identified: WNT7B, CKMT2, AMT, UNQ467, DEFA1, TUBA2, TES, and $U B Q L N 3$. We selected the TES gene as the best candidate gene for further study (Figure 1A). To verify the hypermethylation of TES in GBM, treatment with demethylation reagent 5-aza-dC on the GBM cell line U251 (low TES expression) can greatly increase TES expression (Figure 1B). This result confirms the microarray data that TES is hypermethylated in GBM.

\section{Down-regulation of TES protein expression is in GBM tissues} TES protein expression in GBM was surveyed by immunohistochemistry using anti-TES monoclonal antibody on 37 independent GBM and 10 non-tumor samples. A reduced TES protein level was found in $33(89.2 \%)$ tumor tissues and in $2(20 \%)$ non-tumor tissues $(P<0.001$, Figure 2A). For evaluation of TES protein level, classification standards were as follows: high, $>25 \%$ tumors cells were positively stained, low, no staining or $<25 \%$ tumor cells showed negatively staining. Collectively, these results demonstrated a significant down regulation of TES protein expression in GBM $(P<0.001$, Figure $2 B)$.

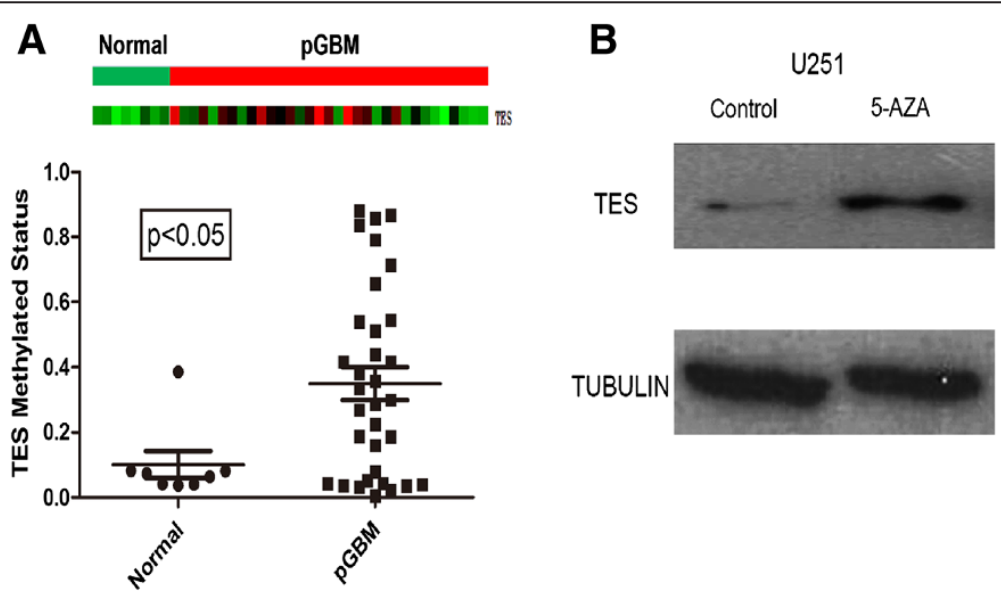

Figure 1 TES promoter methylation status in glioblastoma (GBM, $n=42)$ and normal $(n=8)$ samples analyzed by DNA promoter methylation microarray. (A) Comparison of TES promoter methylation status in GBM and normal samples by microarray analysis (up) and independent $t$-test analysis (down). (B) Western blot of TES in U251 cell line before and after 5-aza-2-deoxycytidine treatment. Anti-tublin was used as a protein loading control. 


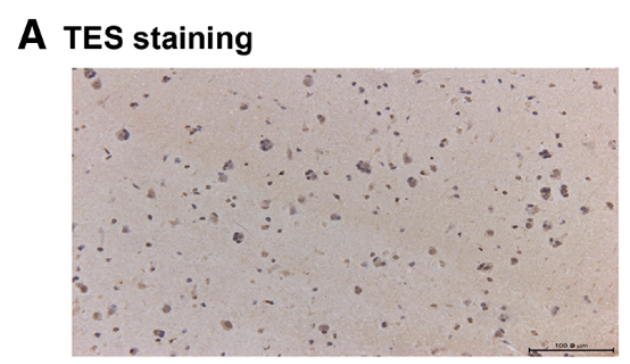

Normal

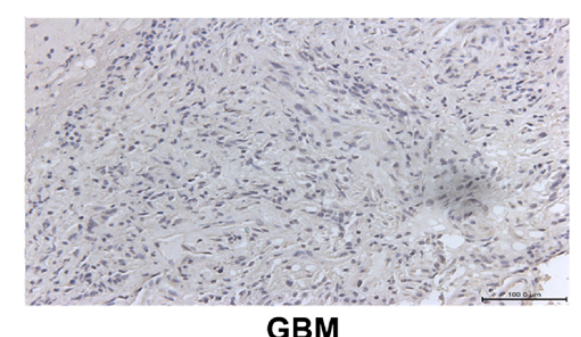

GBM

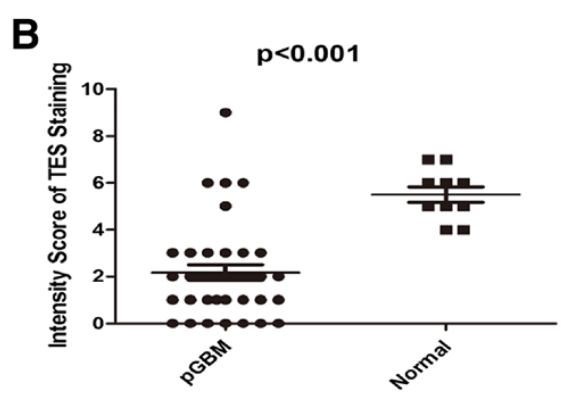

Figure 2 TES expression in GBM. (A) Immunohistochemical staining of TES protein expression in normal tissue (left) and a GBM specimen (right) (magnification 400). (B) Collective summary of TES staining intensity from all samples.

\section{TES enhances apoptosis in glioblastoma cells}

To evaluate pathogenic effect of low expression of TES in GBM, apoptotic effect was assessed on $5 \mu \mathrm{m} 5$-aza$\mathrm{dC}$ treated and untreated U251 cells. The percentage of apoptotic cells was calculated by flow cytometry using the Annexin-V/PI double-staining assay (Figure 3A). In the untreated control group (no 5 -aza-dC was given), the total rate of apoptosis was 8.75 (Figure 3B). However, in U251 cells treated with 5-aza-dC, many more apoptotic cells were detected: the rate raised to 12.25 , suggesting that TES promotes apoptosis of glioblastoma cells.

\section{TES protein expression is highly correlated with worse outcome of GBM patients}

After TES promoter hypermethylation was identified in some GBM patients, we further estimated the association of this abnormality with GBM patients survival using Kaplan-Meier plot, as shown in Figure 4A. Results showed that the overall survival (OS) of patients with TES hypermethylation is significantly shorter than those with hypomethylation (median survival, 236.5 vs. 565 days $P<0.05$, log-rank test). Patient outcome was also evaluated independently from TES protein expression level from results of immunohistochemistry analysis. Patients with high TES expression had a median OS of 221 days, while those with low expression had an OS of 345 days (median survival, 221 vs. 345 days $P<0.05$; Figure 4B). These results suggest that the down-regulation of TES predicts worse outcome of GBM patients and that promoter hypermethylation should be the major reason for TES down-regulation, although mutation, loss of heterozygosity, etc. cannot be excluded.

The elucidation biomarkers of glioblastoma, the most common and lethal of brain tumors, has been reported since the $1990 \mathrm{~s}$. Somatic mutations have been demonstrated for TP53 on 17p [14-16], PTEN on 10q [17-19], $R B 1$ on $13 q[20,21]$, and homozygous deletions of the $C D K N 2 A / p 16 / p 14$ locus on $9 p$ have been documented $[16,22]$. Other putative tumor-suppressor genes alternated at all other loci remain elusive. Methylation of promoter regions inducing silencing of gene expression, has been implicated as an alternative mechanism for tumor-suppressor gene inactivation. In glioblastomas, frequent promoter hypermethylation has been reported for PRDX1 [23,24], WNK2 [24], SGNE1 [25], and ALDH1A3 [26]. Blough et al. demonstrated that 1p Loss silence NHE-1 in oligodendroglioma [27]. Some studies showed the methylation of promoter regions with other alterations. Chou et al. identified hypermethylation of $R B 1$ with IDH1 and IDH2 mutation in gliomas [28].

The TES gene was previously identified as located in the fragile chromosomal region FRA7G at 7q31.2 [29]. Loss of TES expression has been frequently found in various cancers [5,29]. Non-synonymous mutation homozygous deletions have not been observed, consistent with CpG promoter hypermethylation being a mechanism of TES gene inactivation [5]. Previous studies have demonstrated that TES inhibited the growth of breast and uterine cells and promoted ovarian cancer cell apoptosis through caspase-dependent and caspase-independent processes [9,30]. Although TES could be a candidate tumor 
A

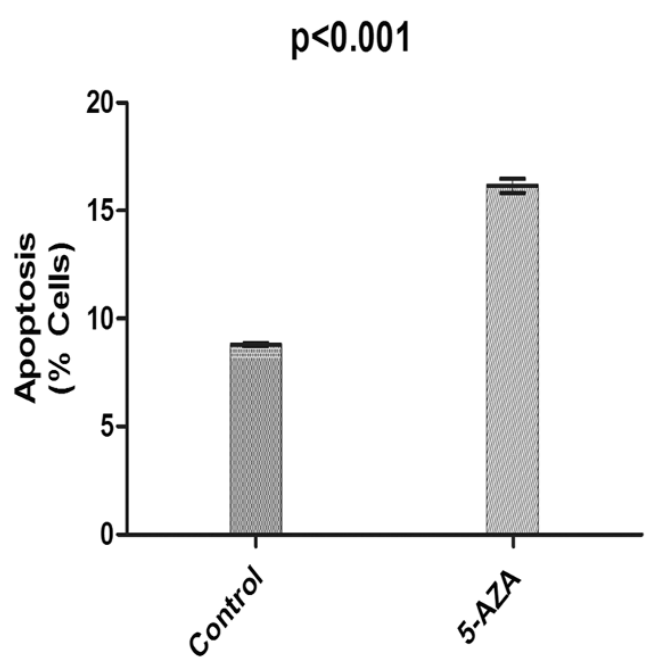

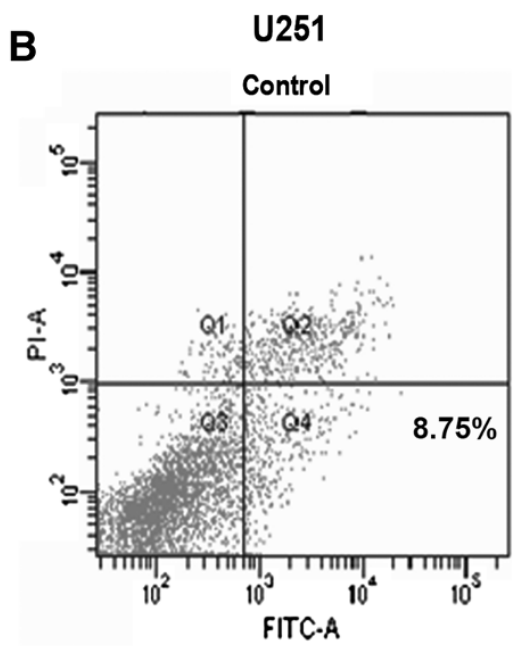

5-AZA

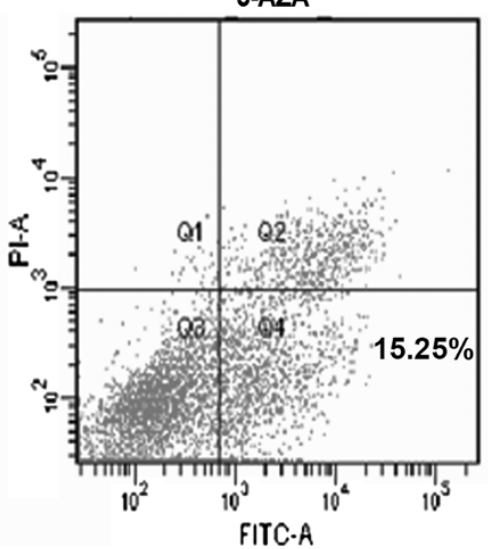

Figure 3 Cell apoptosis induced by treatment of 5-aza-2-deoxycytidine. The percentage of apoptotic cells was calculated by flow cytometry using the Annexin-V/PI double-staining assay. Control vs. 5AZA ( $\left.{ }^{*} P<0.05\right)$. (A) (Control) Apoptosis of U251 cells in the group without 5 -aza-dC treatment (8.75); (B) (5AZA) Apoptosis of U251 cells in the $5 \mathrm{~mL}$ 5-aza-2-dC group (15.25).

suppressor gene in glioma cells, the mechanism of this role is still unknown.

TES, a highly conserved protein, consists of three $\mathrm{C}$-terminal LIM domains and a PET (prickle, espinas, and testin) domain of unknown function. Group 3 LIM domain proteins, including the TES domain, are a component of the focal adhesion complex and localize to cell-matrix adhesions and cell-cell contacts [31]. Over-expression of TES increases cell spreading and decreased cell motility [32]. Adenoviral transduction of the TES gene into breast
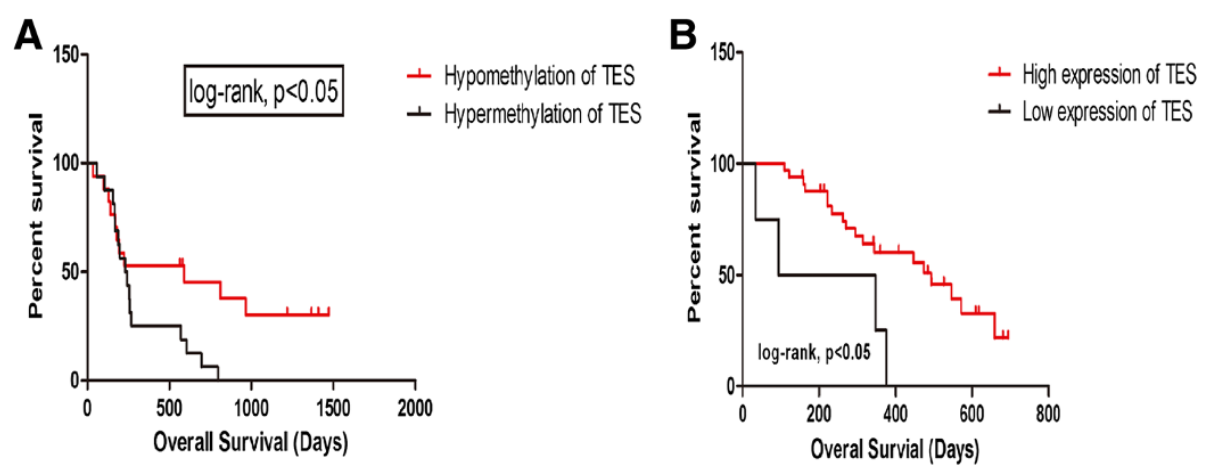

Figure 4 Survial analysis according to TES expression and methylation status. Kaplan-Meier survival estimates of overall survival according to the TES methylation status in 42 GBM patients (A) and according to the TES expression level in GBM patients (B). 
and uterine cancer cell lines promotes apoptosis and tumor reduction [30]. Further functional analysis demonstrated that TES acted as a tumor suppressor gene in vivo, as TES knockout mice showed an increased susceptibility to induced gastric cancer [6]. Our results in this study showed that TES is widely down-regulated in GBM. Elevation of TES expression can increase apoptosis of GBM cells.

TES can be silenced either by loss of heterozygosity or by promoter hypermethylation in several tumor types, including head and neck squamous cell carcinoma, ovarian cancer, primary gastric cancer, prostate cancer, breast cancer, among others [8-12].

Our data suggests promoter hypermethylation is the major cause of down-regulation or silencing of TES in GBM, even if other mechanisms cannot be excluded at this point.

\section{Conclusions}

Using whole-genome DNA methylation microarray we found that the TES gene is a novel tumor suppressor gene and might represent a valuable prognostic marker for glioblastoma, indicating a potential future target for GBM therapy.

\section{Abbreviations}

GBM: Glioblastoma multiform; 5-aza-dC: 5-Aza-2'-deoxycytidine; OS: Overall survival; PBS: Phosphate-buffered saline; PI: Propidium iodide; TES: Testis derived transcript.

\section{Competing interests}

The authors declare that they have no competing interests.

\section{Authors contributions}

YB participated in the design of the study, sample collection, performed Western blotting, flow cytometry analysis of cell apoptosis, and immunohistochemistry analysis, and drafted the manuscript. QGZ performed the statistical analysis, carried out the immunohistochemistry analysis, and helped to revise the manuscript. XHW conceived of the study and participated in its design and coordination, and helped to draft the manuscript. All authors read and approved the final manuscript.

\section{Acknowledgements}

This work was kindly supported in part by the following grants: National Natural Science Foundation of China (81071626, 30872933).

Received: 27 July 2014 Accepted: 17 November 2014

Published online: 11 December 2014

\section{References}

1. Christensen BC, Smith AA, Zheng S, Koestler DC, Houseman EA, Marsit CJ, Wiemels JL, Nelson HH, Karagas MR, Wrensch MR, Kelsey KT, Wiencke JK: DNA methylation, isocitrate dehydrogenase mutation, and survival in glioma. J Natl Cancer Inst 2011, 103:143 153.

2. Dimov I, Tasic-Dimov D, Conic I, Stefanovic V: Glioblastoma multiforme stem cells. Sci World J 2011, 11:930 958.

3. Kanu OO, Mehta A, Di C, Lin N, Bortoff K, Bigner DD, Yan H, Adamson DC: Glioblastoma multiforme: a review of therapeutic targets. Expert Opin Ther Targets 2009, 13:701 718.

4. Noushmehr H, Weisenberger DJ, Diefes K, Phillips HS, Pujara K, Berman BP, Pan F, Pelloski CE, Sulman EP, Bhat KP, Verhaak RG, Hoadley KA, Hayes DN, Perou CM, Schmidt HK, Ding L, Wilson RK, Van Den Berg D, Shen H, Bengtsson H, Neuvial P, Cope LM, Buckley J, Herman JG, Baylin SB, Laird PW Aldape K, Cancer Genome Atlas Research Network: Identification of a CpG island methylator phenotype that defines a distinct subgroup of glioma. Cancer Cell 2010, 17:510 522

5. Tobias ES, Hurlstone AF, MacKenzie E, McFarlane R, Black DM: The TES gene at 7q31.1 is methylated in tumours and encodes a novel growth-suppressing LIM domain protein. Oncogene 2001, 20:2844 2853.

6. Drusco A, Zanesi N, Roldo C, Trapasso F, Farber JL, Fong LY, Croce CM: Knockout mice reveal a tumor suppressor function for Testin. Proc Natl Acad Sci U S A 2005, 102:10947 10951.

7. Griffith E, Coutts AS, Black DM: Characterisation of chicken TES and its role in cell spreading and motility. Cell Motil Cytoskeleton 2004, 57:133 142.

8. Gunduz E, Gunduz M, Beder L, Nagatsuka H, Fukushima K, Sutcu R, Delibas N, Yamanaka N, Shimizu K, Nagai N: Downregulation of TESTIN and its association with cancer history and a tendency toward poor survival in head and neck squamous cell carcinoma. Arch Otolaryngol Head Neck Surg 2009, 135:254 260.

9. Qiu H, Zhu J, Yuan C, Yan S, Yang Q, Kong B: Frequent hypermethylation and loss of heterozygosity of the testis derived transcript gene in ovarian cancer. Cancer Sci 2010, 101:1255 1260.

10. Ma H, Weng D, Chen Y, Huang W, Pan K, Wang H, Xia J: Extensive analysis of D7S486 in primary gastric cancer supports TESTIN as a candidate tumor suppressor gene. Mol Cancer 2010, 9:190.

11. Chene L, Giroud C, Desgrandchamps F, Boccon-Gibod L, Cussenot O, Berthon P, Latil A: Extensive analysis of the 7q31 region in human prostate tumors supports TES as the best candidate tumor suppressor gene. Int $J$ Cancer 2004, 111:798 804.

12. Weeks RJ, Kees UR, Song S, Morison IM: Silencing of TESTIN by dense biallelic promoter methylation is the most common molecular event in childhood acute lymphoblastic leukaemia. Mol Cancer 2010, 9:163.

13. Mueller W, Nutt CL, Ehrich M, Riemenschneider MJ, von Deimling A, van den Boom D, Louis DN: Downregulation of RUNX3 and TES by hypermethylation in glioblastoma. Oncogene 2007, 26:583 593.

14. Chung R, Whaley J, Kley N, Anderson K, Louis D, Menon A, Hettlich C, Freiman R, Hedley-Whyte ET, Martuza R, Jenkins R, Yandell D, Seizinger BR: TP53 gene mutations and 17p deletions in human astrocytomas. Genes Chromosomes Cancer 1991, 3:323 331.

15. von Deimling A, Louis DN, Schramm J, Wiestler OD: Astrocytic gliomas: characterization on a molecular genetic basis. Recent Results Cancer Res 1994, 135:33 42.

16. Ichimura K, Bolin MB, Goike HM, Schmidt EE, Moshref A, Collins VP: Deregulation of the $\mathrm{p} 14 \mathrm{ARF} / \mathrm{MDM} 2 / \mathrm{p} 53$ pathway is a prerequisite for human astrocytic gliomas with G1-S transition control gene abnormalities. Cancer Res 2000, 60:417 424.

17. Li J, Yen C, Liaw D, Podsypanina K, Bose S, Wang SI, PuC J, Miliaresis C, Rodgers L, McCombie R, Bigner SH, Giovanella BC, Ittmann M, Tycko B, Hibshoosh $\mathrm{H}$, Wigler MH, Parsons R: PTEN, a putative protein tyrosine phosphatase gene mutated in human brain, breast, and prostate cancer. Science 1997, 275:1943 1947.

18. Steck PA, Pershouse MA, Jasser SA, Yung WK, Lin H, Ligon AH, Langford LA, Baumgard ML, Hattier T, Davis T, Frye C, Hu R, Swedlund B, Teng DH, Tavtigian SV: Identification of a candidate tumour suppressor gene, MMAC1, at chromosome 10q23.3 that is mutated in multiple advanced cancers. Nat Genet 1997, 15:356 362.

19. Wang SI, PuC J, Li J, Bruce JN, Cairns P, Sidransky D, Parsons R: Somatic mutations of PTEN in glioblastoma multiforme. Cancer Res 1997 57:4183 4186 .

20. Henson JWSB, Correa KM, von Deimling A, Fassbender F, Xu HJ: The retinoblastoma gene is involved in malignant progression of astrocytomas. Ann Neurol 1994, 36:714 721.

21. Ichimura KSE, Goike HM, Collins VP: Human glioblastomas with no alterations of the CDKN2A (p16INK4A, MTS1) and CDK4 genes have frequent mutations of the retinoblastoma gene. Oncogene 1996, 13:1065 1072

22. Ueki K, Ono Y, Henson JW, Efird JT, von Deimling A, Louis DN: CDKN2/p16 or RB alterations occur in the majority of glioblastomas and are inversely correlated. Cancer Res 1996, 56:150 153.

23. Dittmann LM, Danner A, Gronych J, Wolter M, Stuhler K, Grzendowski M, Becker N, Bageritz J, Goidts V, Toedt G, Felsberg J, Sabel MC, Barbus S, Reifenberger G, Lichter P, Tews B: Downregulation of PRDX1 by promoter hypermethylation is frequent in $1 \mathrm{p} / 19 \mathrm{q}$-deleted oligodendroglial tumours and increases radio- and chemosensitivity of $\mathrm{Hs} 683$ glioma cells in vitro. Oncogene 2012, 31:3409 3418. 
24. Moniz S, Martinho O, Pinto F, Sousa B, Loureiro C, Oliveira MJ, Moita LF, Honavar M, Pinheiro C, Pires M, Lopes JM, Jones C, Costello JF, Paredes J, Reis RM, Jordan P: Loss of WNK2 expression by promoter gene methylation occurs in adult gliomas and triggers Rac1-mediated tumour cell invasiveness. Hum Mol Genet 2013, 22(1):84 95.

25. Waha A, Felsberg J, Hartmann W, Hammes J, von dem Knesebeck A, Endl E, Pietsch T, Waha A: Frequent epigenetic inactivation of the chaperone SGNE1/7B2 in human gliomas. Int I Cancer 2012, 131:612 622.

26. Zhang W, Yan W, You G, Bao Z, Wang Y, Liu Y, You Y, Jiang T: Genome-wide DNA methylation profiling identifies ALDH1A3 promoter methylation as a prognostic predictor in G-CIMP- primary glioblastoma. Cancer Lett 2013, 328:120 125.

27. Blough MD, Al-Najjar M, Chesnelong C, Binding CE, Rogers AD, Luchman HA Kelly JJ, Fliegel L, Morozova O, Yip S, Marra M, Weiss S, Chan JA, Cairncross JG DNA hypermethylation and 1p Loss silence NHE-1 in oligodendroglioma. Ann Neurol 2012, 71:845 849.

28. Chou AP, Chowdhury R, Li S, Chen W, Kim AJ, Piccioni DE, Selfridge JM, Mody RR, Chang S, Lalezari S, Lin J, Sanchez DE, Wilson RW, Garrett MC, Harry B, Mottahedeh J, Nghiemphu PL, Kornblum HI, Mischel PS, Prins RM, Yong WH, Cloughesy T, Nelson SF, Liau LM, Lai A: Identification of retinol binding protein 1 promoter hypermethylation in isocitrate dehydrogenase 1 and 2 mutant gliomas. J Natl Cancer Inst 2012, 104:1458 1469.

29. Tatarelli C, Linnenbach A, Mimori K, Croce CM: Characterization of the human TESTIN gene localized in the FRA7G region at 7q31.2. Genomics 2000, 68:1 12.

30. Sarti M, Sevignani C, Calin GA, Ageilan R, Shimizu M, Pentimalli F, Picchio MC, Godwin A, Rosenberg A, Drusco A, Negrini M, Croce CM: Adenoviral transduction of TESTIN gene into breast and uterine cancer cell lines promotes apoptosis and tumor reduction in vivo. Clin Cancer Res 2005, 11:806 813.

31. Coutts AME, Griffith E, Black D: TES is a novel focal adhesion protein with a role in cell spreading. J Cell Sci 2003, 116:897 906.

32. Boeda B, Briggs DC, Higgins T, Garvalov BK, Fadden AJ, McDonald NQ, Way M: Tes, a specific Mena interacting partner, breaks the rules for EVH1 binding. Mol Cell 2007, 28:1071 1082

doi:10.1186/s40001-014-0066-4

Cite this article as: Bai et al:: Downregulation of TES by

hypermethylation in glioblastoma reduces cell apoptosis and predicts poor clinical outcome. European Journal of Medical Research 2014 19:66.

\section{Submit your next manuscript to BioMed Central and take full advantage of:}

$\bowtie$ Convenient online submission

$\otimes$ Thorough peer review

$\otimes$ No space constraints or color $\nabla$ gure charges

$\bigotimes$ Immediate publication on acceptance

Q Inclusion in PubMed, CAS, Scopus and Google Scholar

$\otimes$ Research which is freely available for redistribution 